\title{
Jacky Milewski, Les fêtes de pèlerinage dans la tradition juive
}

Paris, Presses universitaires de France, coll. « Lectures du judaïsme », 2011, $156 \mathrm{p}$.

Yves Chevalier

\section{(2) OpenEdition}

Journals

Édition électronique

URL : http://journals.openedition.org/assr/24660

DOI : $10.4000 /$ assr. 24660

ISSN : $1777-5825$

Éditeur

Éditions de l'EHESS

Édition imprimée

Date de publication : 30 décembre 2012

Pagination : 243

ISSN : 0335-5985

Référence électronique

Yves Chevalier, "Jacky Milewski, Les fêtes de pèlerinage dans la tradition juive ", Archives de sciences sociales des religions [En ligne], 160 | octobre-décembre 2012, mis en ligne le 19 mars 2013, consulté le 21 septembre 2020. URL : http://journals.openedition.org/assr/24660 ; DOI : https://doi.org/10.4000/ assr.24660

Ce document a été généré automatiquement le 21 septembre 2020.

(c) Archives de sciences sociales des religions 


\section{Jacky Milewski, Les fêtes de pèlerinage dans la tradition juive}

Paris, Presses universitaires de France, coll. « Lectures du judaïsme », 2011, $156 \mathrm{p}$.

Yves Chevalier

\section{RÉFÉRENCE}

Jacky Milewski, Les fêtes de pèlerinage dans la tradition juive, Paris, Presses universitaires de France, coll. « Lectures du judaïsme », 2011, 156 p. 
1 Les Presses universitaires de France inaugurent avec cet ouvrage une nouvelle collection en format de poche : « Lectures du Judaïsme », publiée avec le concours de l'Institut universitaire d'Études juives Elie Wiesel. Hervé Landau, qui la dirige, explique son originalité dans le paysage des études francophones du judaïsme par trois caractéristiques: il s'agit de proposer à de nouveaux auteurs, de formation universitaire ou rabbinique (souvent les deux), d'aborder d'une manière neuve les thèmes fondamentaux

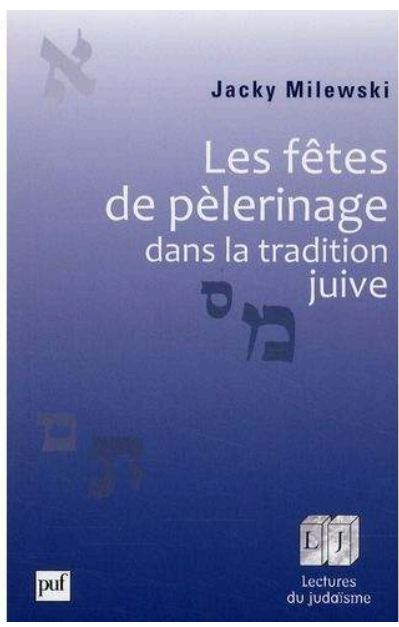
$\mathrm{du}$ judaïsme, à la fois en montrant comment ils ont été saisis au cours des siècles (d'où une attention au caractère cumulatif de la réflexion) et en les rendant actuels pour en faciliter l'accès à nos contemporains.

2 Le premier volume de cette collection a donc été demandé au rabbin Jacky Milewski, à la fois diplômé du Séminaire israélite de France et Docteur en droit, auteur d'une thèse sur l'argumentation et l'éthique dans le droit talmudique et de plusieurs ouvrages portant sur les significations éthiques et morales des normes dans le judaïsme. Ce volume est consacré aux trois fêtes de pèlerinages : Pessa'h (la Pâque) au printemps, qui commémore la sortie d'Égypte; Chavou'ot (les «Semaines » ou Pentecôte) au moment des moissons, célébrant le don de la Torah au Sinaï; Soucot (des Cabanes ou des Tabernacles) au début de l'automne, pour rappeler les quatre décennies de pérégrination dans le désert. Ce sont des fêtes de "convocation " - dans le temps et dans l'espace - qui invitent toute la nation (les hommes religieusement majeurs) à la rencontre avec Dieu. Leurs significations, peu explicitées dans le texte biblique, ont été progressivement dégagées à travers la littérature talmudique et rabbinique, cette dernière insistant en particulier sur les préoccupations pédagogiques du rituel de ces trois fêtes.

3 L'auteur étudie d'abord les présentations de ces trois fêtes dans quatre des livres du Pentateuque: Exode, Lévitique, Nombres et Deutéronome (Torah écrite) et dans les commentaires talmudiques (Torah orale) où un certain nombre d'explications viennent préciser le sens de chacune de ces fêtes (qui renvoient à des événements fondateurs de l'être juif) et de leurs caractéristiques propres. Il poursuit par l'étude à travers les siècles des développements de la réflexion : au Moyen Âge, l'insistance porte sur « la rencontre " et sur la nécessité «de se réjouir»; à la Renaissance, l'accent des commentateurs porte sur le message collectif et individuel que véhicule chaque fête, qui enseigne à l'homme à se situer dans le monde et par rapport à Dieu. Ainsi est progressivement explicité le sens symbolique des éléments constitutifs de ces fêtes et des gestes du rituel. En terminant, l'auteur s'interroge sur la "modernité » de ces fêtes de pèlerinages qui, selon son analyse, évoquent toutes la problématique de l'image si présente dans la société occidentale. On comprendra mieux comment un certain nombre de nos contemporains peuvent n'éprouver aucun anachronisme à se plier à ces rituels plurimillénaires qui sont porteurs de sens. 